\title{
Contraceptive options for women with premenstrual dysphoric disorder: current insights and a narrative review
}

This article was published in the following Dove Press journal:

Open Access Journal of Contraception

25 August 2016

Number of times this article has been viewed

\author{
Iñaki Lete ${ }^{1-3}$ \\ Oihane Lapuente ${ }^{1,2}$ \\ 'Department of Obstetrics and \\ Gynecology, University Hospital \\ Araba, ${ }^{2}$ Bioaraba Research Unit, \\ ${ }^{3}$ School of Medicine, Basque Country \\ University, Vitoria, Spain
}

\begin{abstract}
Premenstrual syndrome and its most severe form, premenstrual dysphoric disorder (PMDD), are two well-defined clinical entities that affect a considerable number of women. Progesterone metabolites and certain neurotransmitters, such as gamma-aminobutyric acid and serotonin, are involved in the etiology of this condition. Until recently, the only treatment for women with PMDD was psychoactive drugs, such as selective serotonin reuptake inhibitors. Several years ago, there has been evidence of the beneficial role of combined hormonal contraceptives in controlling PMDD symptoms. Oral combined hormonal contraceptives that contain drospirenone in a 24+4-day regimen are the only drugs that have been approved by US Food and Drug Administration for the treatment of PMDD, but there is scientific evidence that other agents, with other formulations and regimens, could also be effective for the treatment of this condition. However, it remains unclear whether the beneficial effect of combined hormonal contraceptives is associated with the type of estrogen or progestogen used or the treatment regimen. Keywords: premenstrual syndrome, premenstrual dysphoric disorder, hormonal contraceptives, drospirenone, estradiol
\end{abstract}

\section{Premenstrual syndrome and premenstrual dysphoric disorder Introduction}

It is difficult to conduct a review of the potential impact of the use of combined hormonal contraceptives (CHCs) for premenstrual syndrome (PMS) and premenstrual dysphoric disorder (PMDD) due to heterogeneity between clinical studies. In many studies, the populations analyzed are not well defined, and hence, there is insufficient information to determine whether women included had premenstrual symptoms, PMS, or PMDD or a combination thereof. Another of the difficulties for the analysis arises from the fact that clinical studies have used different instruments to assess PMS and PMDD, and results may vary depending on the scale used.

\section{Definition}

PMS or premenstrual tension is a poorly defined clinical entity that encompasses a wide variety of luteal phase symptoms that are bothersome and usually disappear or greatly improve shortly after the onset of bleeding. ${ }^{1}$ The characteristic symptoms are a mix of mood and physical and cognitive disturbances. The severity and frequency of the symptoms seem to be quite variable, and they may vary in the same woman from month to month. As many as $80 \%$ of women experience mood and physical symptoms
Correspondence: Iñaki Lete

Department of Obstetrics and

Gynecology, University Hospital Araba, José Atxotegui s/n, 01009 Vitoria, Spain

Tel +34945007204

$\mathrm{Fax}+34945007901$

Email luisignacio.letelasa@osakidetza.net 
associated with the menstrual cycle, ${ }^{2}$ and epidemiological studies have shown that for $24 \%-32 \%$ of menstruating women, the symptoms are moderate or severe. ${ }^{3}$ PMDD is a more severe form of PMS, affecting 5.8\% of women aged 14-24 years. ${ }^{4}$ PMDD is not a culture-bound syndrome and has been observed in women from the US and Europe to India and elsewhere in Asia. Although PMS is widely recognized, the etiology remains unclear and it lacks definitive, universally accepted diagnostic criteria. In the 10th edition of the International Classification of Diseases of the World Health Organization, ${ }^{5}$ premenstrual tension syndrome is classified as a gynecological disorder, and the definition requires only one symptom to be present from a list of seven physical and emotional symptoms. However, the description of the syndrome is very vague and does not specify the critical issue of symptom severity or the level of impairment. ${ }^{6}$ In Table 1, we list the Diagnostic and Statistical Manual of Mental Disorders, fifth edition, ${ }^{7}$ requirements for the diagnosis of PMDD.

In brief, PMDD is the most severe form of PMS and, as such, warrants a distinct approach. Table 2 presents the criteria developed by Steiner et al ${ }^{8}$ for the diagnosis of PMS and PMDD.

\section{Etiology}

Although the cause of PMS is not fully understood, there are various theories suggesting the involvement of several hormones and neurotransmitters. In particular, ovarian steroid hormones appear to play an important role in this syndrome. Women with PMS/PMDD seem to have more symptoms with normal cyclical levels of steroid hormones; however, during anovulatory cycles, these symptoms are not observed. ${ }^{9}$ In a study in which 20 women diagnosed with PMS and 15 women without PMS were treated with a gonadotropinreleasing hormone analog (leuprolide) or placebo, a significant improvement was observed in the parameters related to PMS in the leuprolide group; this effect disappeared after administration of steroid hormones (transdermal estradiol and vaginal progesterone). ${ }^{10}$ The researchers concluded that women with PMS have an aberrant central nervous system response to steroid hormones. ${ }^{10}$

There is evidence of a relationship between this syndrome and changes in certain progesterone metabolites (pregnenolone and allopregnanolone) during the menstrual cycle. ${ }^{11}$ Neurotransmitters, especially gamma-aminobutyric acid (GABA) and serotonin, seem to be involved in the manifestations of PMS/PMDD. GABA is an important regulator of stress, anxiety, and alertness, among other states, ${ }^{9}$ and the aforementioned progesterone metabolites (pregnenolone and allopregnanolone) act as positive modulators of the GABAergic system in the brain. Deficiency in these metabolites appears to be related to this syndrome. Specifically, some

Table I Diagnostic and Statistical Manual of Mental Disorders, fifth edition, requirements for the diagnosis of PMDD

A. In the majority of menstrual cycles, at least five symptoms must be present in the final week before the onset of menses, start to improve within a few days after the onset of menses, and become minimal or absent in the week post menses.

B. One (or more) of the following symptoms must be present:

I. Marked affective lability (eg, mood swings; feeling suddenly sad or tearful, or increased sensitivity to rejection).

2. Marked irritability or anger or increased interpersonal conflicts.

3. Marked depressed mood, feelings of hopelessness, or self-deprecating thoughts.

4. Marked anxiety, tension, and/or feelings of being keyed up or on edge.

C. One (or more) of the following symptoms must additionally be present, to reach a total of five symptoms when combined with symptoms from Criterion B above.

I. Decreased interest in usual activities (eg, work, school, friends, hobbies).

2. Subjective difficulty in concentration.

3. Lethargy, easy fatigability, or marked lack of energy.

4. Marked change in appetite, overeating, or specific food cravings.

5. Hypersomnia or insomnia.

6. A sense of being overwhelmed or out of control.

7. Physical symptoms such as breast tenderness or swelling, joint or muscle pain, a sensation of "bloating," or weight gain.

D. The symptoms are associated with clinically significant distress or interference with work, school, usual social activities, or relationships with others (eg, avoidance of social activities; decreased productivity and efficiency at work, school, or home).

E. The disturbance is not merely an exacerbation of the symptoms of another disorder, such as major depressive disorder, panic disorder, persistent depressive disorder (dysthymia), or a personality disorder (although it may co-occur with any of these disorders).

F. Criterion A should be confirmed by prospective daily ratings during at least two symptomatic cycles. (Note: The diagnosis may be made provisionally prior to this confirmation.)

G. The symptoms are not attributable to the physiological effects of a substance (eg, a drug of abuse, a medication, other treatment) or another medical condition (eg, hyperthyroidism).

Note: The symptoms in Criteria A-C must have been met for most menstrual cycles that occurred in the preceding year. Data from American Psychiatric Association. ${ }^{7}$ Abbreviation: PMDD, premenstrual dysphoric disorder. 
Table 2 The Premenstrual Symptom Screening Tool

Do you experience some or any of the following premenstrual symptoms which start before your period and stop within a few days of bleeding? Please mark an $\mathbf{X}$ in the appropriate box.

\begin{tabular}{l}
\hline Symptom \\
I. Anger/irritability \\
2. Anxiety/tension \\
3. Tearful/increased sensitivity to rejection \\
4. Depressed mood/hopelessness \\
5. Decreased interest in work activities \\
6. Decreased interest in home activities \\
7. Decreased interest in social activities \\
8. Difficulty concentrating \\
9. Fatigue/lack of energy \\
10. Overeating/food cravings \\
II. Insomnia \\
12. Hypersomnia (needing more sleep) \\
13. Feeling overwhelmed or out of control \\
14. Physical symptoms: breast tenderness, headaches, joint/muscle pain, \\
bloating, weight gain \\
Have your symptoms interfered with: \\
A. Work efficiency or productivity \\
B. Relationships with coworkers \\
C. Relationships with the family \\
D. Social life activities \\
E. Home responsibilities
\end{tabular}

Notes: Scoring: the following criteria must be present for a diagnosis of moderate-to-severe PMS: I) At least one of I, 2, 3, and 4 is moderate to severe. 2) In addition, at least four of $\mathrm{I}-14$ are moderate to severe. 3) At least one of $A, B, C, D$, and $E$ is moderate to severe. The following criteria must be present for a diagnosis of PMDD: I) At least one of I, 2, 3, and 4 is severe. 2) In addition, at least four of $I-I 4$ are moderate to severe. 3) At least one of $A, B, C, D$, and $E$ is severe. Data from Steiner et al. ${ }^{8}$ Abbreviations: PMS, premenstrual syndrome; PMDD, premenstrual dysphoric disorder.

studies have found the GABA receptor to be less receptive and have found lower levels of this substance during the luteal phase of the menstrual cycle, ${ }^{12}$ and this may explain the potential beneficial effect of the use of CHCs in the treatment of this condition.

Additionally, serotonergic function seems to be altered in the luteal phase of the menstrual cycle in women with PMS/PMDD. Depletion of serotonin levels is associated with anxiety and depressive symptoms. The efficacy of selective serotonin reuptake inhibitors (SSRIs) for PMS supports the view that serotonin is involved in this syndrome. ${ }^{13}$ It has also been suggested that serotonin deficiency, common in women with PMS, increases sensitivity to progesterone. ${ }^{14}$

Finally, neuroanatomical studies performed using magnetic resonance imaging have found changes in limbic system function in women with PMDD, confirming the biological basis of this clinical entity. ${ }^{15}$

\section{Clinical picture}

Women with PMS have a wide variety of physical, emotional, cognitive, and behavioral symptoms that start in the luteal phase of the menstrual cycle and disappear after menstruation (Table 3). Symptoms vary in terms of severity, in some cases limiting activities of daily living and personal relationships, with PMDD being the most severe presentation of this condition. ${ }^{16}$ In a study by our group in Spain, ${ }^{17} 1,554(73.7 \%)$ of the 2,108 women included had had some of the symptoms characteristic of PMS during at least one of their last 12 menstrual cycles, 429 (20.3\%) were asymptomatic, and 93 $(4.4 \%)$ had had some of the symptoms in the past but not in the last 12 cycles, while $32(1.5 \%)$ did not respond. The most frequent premenstrual symptoms were physical complaints (breast tenderness, headache, weight gain, and/or bloating), occurring in $81.6 \%$ of women, followed by irritability $(53 \%)$, tearfulness (48.7\%), and anxiety (40.5\%). The total of $73.7 \%$ of women with some premenstrual symptoms in the last 12 menstrual cycles was higher than the $50.1 \%$ observed in the study of Adewuya et al. ${ }^{18}$

In a community-based sample of women in the US, UK, and France, irritability/anger, fatigue, physical swelling/ bloating, and/or weight gain were among the most commonly reported symptoms, being present in $\sim 80 \%$ of cases.

The problem of PMS is its potential impact on the quality of life of women who have it and the consequences it may have in terms of their physical, emotional, and work-related activities. Specifically, the importance of PMS is related to its potential impact on the activities of daily living of women during the luteal phase of their menstrual cycle. ${ }^{19}$ Despite 
Table 3 Symptoms described by women suffering PMS or PMDD

\begin{tabular}{lll}
\hline Physical & Behavioral & Mood \\
\hline Swelling & Sleep disturbances & Irritability \\
Breast tenderness & Appetite changes & Mood swings \\
General aches & Poor concentration & Anxiety \\
Headache & Decreased interest & Depression \\
Weight gain & Social withdrawal & Loss of self-control \\
Feeling bloated & & \\
\hline
\end{tabular}

Note: Data from Freedman. ${ }^{16}$

Abbreviations: PMS, premenstrual syndrome; PMDD, premenstrual dysphoric disorder.

social awareness of this condition and its recognition by scientific societies, a large percentage of women who experience PMS do not seek medical attention, and this is a problem as it means that they are not appropriately diagnosed or treated. ${ }^{20}$

\section{Materials and methods}

This is a narrative review about the effect of hormonal contraceptives on PMS and PMDD. We performed a search in MEDLINE using the following MeSH terms: premenstrual syndrome and hormonal contraceptives.

\section{Treatment of PMS and PMDD}

In general, the recommended first-line treatment is SSRIs, since this type of medication is effective in reducing symptoms of PMS both when taken exclusively during the luteal phase of the cycle and when they are taken continuously, ${ }^{21}$ US Food and Drug Administration having authorized the use of fluoxetine, sertraline, and paroxetine.

On the other hand, despite SSRIs being effective in most cases, many women decline this type of treatment and prefer other options, given that PMS affects women of childbearing age and these drugs do not provide contraceptive protection, as well as the negative perception of the use of psychoactive drugs. ${ }^{20}$ Further, as many as $15 \%$ of those who do take SSRIs experience dose-dependent adverse effects, and these are the main reasons for abandoning treatment. ${ }^{22,23}$

Alternatives to SSRIs in these patients include diuretics, such as spironolactone, with effects that are based on reducing water retention. ${ }^{24}$ In addition, the administration of progesterone and progestogens in the luteal phase has been proposed as a potential treatment, based on the hypothesis that a deficiency of progesterone and its derivatives in this phase causes PMS. So far, however, there is a lack of evidence of their effectiveness in the treatment of this syndrome, ${ }^{25}$ and it has even been suggested that they may even aggravate symptoms. ${ }^{26}$

We should also consider the evidence concerning the effectiveness of alternative therapies including acupuncture and herbal medicine. A systematic review identified four clinical trials on the effect of acupuncture on PMDD: although all four suggested an improvement in symptoms associated with acupuncture treatment, the limitations of the studies preclude definitive conclusion. ${ }^{27}$ Regarding herbal medicine, it has been suggested that women with PMS may have a deficiency of gamma-linoleic acid. Good results have been observed with combination of evening primrose oil, which has a high content of gamma-linoleic acid, and pyridoxine (100-150 mg/d), but given the poor quality of the research, further studies are required to confirm the efficacy of this treatment. ${ }^{28}$ Two randomized double-blind studies on the effect of homeopathy on PMS have been reported. The outcomes were better with homeopathy than placebo, although the findings were contradictory. ${ }^{29}$

\section{Treatment with $\mathrm{CHCs}$}

PMS and PMDD affect young women, of childbearing age, who often wish to avoid becoming pregnant. In this context, CHCs could be a good option for such women if they were found to alleviate symptoms of PMS as well as proving effective contraception.

The involvement of steroid hormones in the genesis of PMS lends further support to the idea of using CHCs. Traditionally, combined oral contraceptives (COCs) have not been considered an effective treatment for PMS, despite these drugs having shown beneficial effects on the somatic symptoms of PMS, ${ }^{30}$ and there being some evidence of other beneficial effects, although from low-quality studies.

In a nested case-control study within a community-based cohort of 976 premenopausal women in Massachusetts, $12.3 \%$ of 658 women who were using oral contraceptive pills reported premenstrual mood improvement, but $16.3 \%$ reported oral contraceptive pill-related premenstrual mood deterioration. Previous depression was the only significant predictor of mood deterioration (odds ratio: 2.0, 95\% confidence interval: 1.1-3.8). It was concluded that oral contraceptive pills do not influence premenstrual mood in most women. ${ }^{31}$ Similarly, in a cross-sectional study of 181 Australian women from the general community (mean age: 30 years) who completed the Moos Menstrual Distress Questionnaire, no association was found between use of the oral contraceptive pill and the incidence or severity of PMS. ${ }^{32}$

PMS and PMDD do not occur in women who are pregnant, who do not have ovaries, or who have the menopause,,$^{13}$ and hence, it seems appropriate to use treatments to reduce ovarian activity, and $\mathrm{CHCs}$ are the easiest and fastest way to achieve an anovulatory cycle. ${ }^{10}$ Clearly, however, assessing 
the efficacy of CHCs in PMS may be difficult given that there are various types of $\mathrm{CHCs}$, with potentially relevant differences in their characteristics. The main differences between CHCs are outlined in Table 4.

The large variety of pharmaceutical formulations, presentations, and doses makes it difficult to reach a conclusion regarding the beneficial effect of CHCs in PMS. There is uncertainty concerning whether the beneficial effect depends on the type of progestogen, the type and/or dose of estrogen, or the regimen.

\section{Effect of CHC progestogens on PMS}

Progestogens can bind to various types of receptors including those for estrogens, androgens, glucocorticoids, and mineralocorticoids, as well as progestogens, and hence, they are involved in a range of different biological activities. ${ }^{33}$ Given that some PMS symptoms occur when there is a reduction in the plasma levels of progesterone produced by the corpus luteum, as a consequence of its metabolites pregnenolone and allopregnanolone, it was thought that exogenous progesterone or progestogen might have a beneficial effect on women with PMS. ${ }^{34}$

Among the progestogens available for use in $\mathrm{CHCs}$, drosperinone is a derivative of spironolactone with similar properties, namely, antimineralocorticoid activity and a diuretic effect, ${ }^{35}$ and seems to be a good candidate for use in patients with PMS. In line with its antimineralocorticoid activity, women treated with drosperinone have smaller changes in blood pressure and body weight and a lower rate of breast pain. ${ }^{36}$ The effect on PMS of oral contraceptives containing a combination of ethinyl estradiol (EE) and drosperinone was assessed in a prospective, noncomparative study of 13 treatment cycles followed up in 326 women. ${ }^{37}$ Symptoms related to menstruation were assessed at baseline

Table 4 Different types of $\mathrm{CHCs}$

I. Dose of EE: The CHCs currently available are based on doses of between $15 \mu \mathrm{g}$ and $50 \mu \mathrm{g}$ of $\mathrm{EE}$

2. Type and dose of progestogen: progestogens used for contraception can be derived from the following three sources

2.I. $17 \mathrm{OH}$ progesterone

2.2. 19 Nortestosterone

2.3. Spironolactone

3. Regimen of administration: To date, treatments are based on $2 \mathrm{I}$ days of intake of the active ingredient and a hormone-free interval of 7 days or other patterns such as $22+6,24+4$, or $26+2$, as well as extended and continuous regimens

4. Route of administration. CHCs can be administered orally, transdermally, vaginally, or by IM or SC injection

Abbreviations: $\mathrm{CHCs}$, combined hormonal contraceptives; $\mathrm{EE}$, ethinyl estradiol IM, intramuscular; SC, subcutaneous. and after six treatment cycles using the Menstrual Distress Questionnaire, and significant reduction in symptoms was found in all the women included.

$\mathrm{CHC}$ with drosperinone has also been analyzed in the framework of several comparison studies. The first study was published in 2001 by Freeman et $\mathrm{al}^{38}$ and included 82 women with PMDD. These patients were randomly allocated to a group receiving oral contraception based on $30 \mu \mathrm{g}$ of EE and $3 \mathrm{mg}$ of drosperinone in a 21/7 regimen or to a placebo group for three cycles. The symptoms associated with PMDD were assessed using the calendar of premenstrual experiences (COPE), the Beck depression inventory (BDI), and the profile of mood states (POMS). Although total COPE scores were better (lower) in the drosperinone/EE group than the placebo group, the differences were not significant, except in scale 3 that collects data on acne, appetite, and food craving. Similarly, the BDI and POMS scores were better in the drospirenone/EE group, but the differences were not significant.

In 2005, the results were published from a multicenter double-blind randomized crossover study comparing a COC treatment composed of $20 \mu \mathrm{g}$ of EE and $3 \mathrm{mg}$ of drospirenone in a 24/4 regimen with placebo. ${ }^{39}$ Sixty-four patients with PMDD included in the study were randomly allocated to first take either the COC or the placebo, and after three cycles of use and one cycle for clearance, swap to the other treatment, placebo for those who have taken the COC and COC for those who have taken placebo. The symptoms associated with PMDD were assessed using different scales to those used in the study of Freeman et $\mathrm{al}^{38}$ : the Daily Record of Severity of Problems, the Endicott Quality of Life Enjoyment and Satisfaction Questionnaire, the Clinical Global Impressions - Improvement scale, and the Premenstrual Tension Scale. The study found significant differences, in favor of the COC containing drospirenone, with all the instruments used to assess PMDD symptoms.

Another multicenter double-blind randomized study of 450 women comparing the same drug in the same regimen (a contraceptive composed of $20 \mu \mathrm{g}$ of EE and $3 \mathrm{mg}$ of drospirenone in a 24/4 regimen) with placebo using the same measurement instruments also found a significantly better response in PMS and PMDD symptoms in the treatment group than in the placebo group. ${ }^{40}$

Nevertheless, a subsequent Cochrane review, based on five studies and 1,920 women, concluded that contraceptive treatment with $20 \mu \mathrm{g}$ of $\mathrm{EE}$ and $3 \mathrm{mg}$ of drospirenone in a 24/4 regimen may be effective in women with PMDD but that placebo also has a marked effect. Further, it was concluded that there was insufficient evidence to establish whether the 
COC in question was better for the control and treatment of PMS and PMDD than other COCs, with different progestogens, and it is not known whether COCs are useful for women with milder forms of PMS. ${ }^{41}$

As well as from the three aforementioned studies (by Freeman et $a l,{ }^{38}$ Pearlstein et $\mathrm{al}^{39}{ }^{39}$ and Yonkers et $\mathrm{al}^{40}$ ), this Cochrane review obtained data from three other studies that compared one drospirenone-based oral COC with another using a different progestogen. The first of these trials was an international multicenter open-label randomized study that compared the effect of two COCs in a 21/7 regimen, one containing $30 \mu \mathrm{g}$ of EE and $3 \mathrm{mg}$ of drospirenone and the other $30 \mu \mathrm{g}$ of EE and $150 \mu \mathrm{g}$ of desogestrel (DSG), on PMS in a sample of 900 women (450 individuals per group) over 26 menstrual cycles. ${ }^{42}$ At the end of the follow-up, no significant differences were observed between the groups in some symptoms associated with PMS (headache and breast pain). In the second trial, conducted by Kelly et al, ${ }^{43}$ 424 women with PMS were randomly allocated to receive a COC containing either $30 \mu \mathrm{g}$ of $\mathrm{EE}$ and $3 \mathrm{mg}$ of drospirenone $(\mathrm{n}=282)$ or $30 \mu \mathrm{g}$ of $\mathrm{EE} / 150 \mu \mathrm{g}$ of levonorgestrel (LNG) $(n=142)$, in a 21/7 regimen in both groups, over seven cycles. The premenstrual symptoms were measured using the Menstrual Distress Questionnaire, and again no significant differences were observed between groups.

More recently, a randomized open-label clinical trial (published in 2013) analyzed 90 women with PMS who were randomly allocated to receive either $20 \mu \mathrm{g}$ of EE and $3 \mathrm{mg}$ of drospirenone or $20 \mu \mathrm{g}$ of EE and $150 \mu \mathrm{g}$ of DSG, in a 24/4 regimen (in both cases), over six cycles. Symptoms were assessed using the Women's Health Assessment Questionnaire in both groups in the premenstrual, menstrual, and postmenstrual phases. In the drospirenone group, at the end of the third and sixth cycles, a significant reduction in the symptoms was observed for all phases, and symptom scores were lower than in the DSG group. In the DSG group, there was also a significant reduction in clinical signs after the sixth cycle in the premenstrual and menstrual phases. That is, both treatments were found to reduce premenstrual signs, but the drospirenone-based treatment showed greater efficacy, and the effect was more rapid. ${ }^{44}$

According to the available evidence, although it seems that while drospirenone is a very suitable progestogen to be combined with EE in cases of PMDD and PMS, a similar positive effect can also be obtained using other contraceptive formulations containing different progestogens. Hence, it remains unclear what is the real role of drospirenone and whether the beneficial effect can also be achieved with other progestogens without antimineralocorticoid properties.

\section{Effect of the CHC regimen on PMS}

One of the strategies considered in the treatment of PMS has been to reduce the hormone-free interval (HFI), given that it is known that CHCs with a shorter HFI lead to a more marked suppression of ovarian activity and, as a consequence, less fluctuation in endogenous levels of steroid and anterior pituitary hormones. ${ }^{45}$ For this reason, CHC treatments with shorter HFIs have been proposed, especially in $24 / 4$ regimens. ${ }^{46}$

A double-blind randomized clinical trial assessed the severity of the symptoms associated with the HFI (hormone withdrawal-associated symptoms) using a self-report Likert scale in 290 patients given a CHC containing $20 \mu \mathrm{g}$ of EE and $3 \mathrm{mg}$ of drospirenone in a 24/4 regimen and 304 patients given a CHC with $20 \mu \mathrm{g}$ of EE and $150 \mu \mathrm{g}$ of DSG in a 21/7 regimen. No differences were observed in the decrease in symptoms between the treatment groups $(P=0.2045) .{ }^{47}$

Returning to studies previously mentioned, Pearlstein et $\mathrm{al}^{39}$ and Yonkers et al, ${ }^{40}$ who compared an oral $\mathrm{CHC}$ containing $20 \mu \mathrm{g}$ of $\mathrm{EE}$ and $3 \mathrm{mg}$ of drospirenone in a 24/4 regimen with placebo, found significantly lower levels of symptoms, unlike Freeman et al. ${ }^{38}$ The difference may have been due to the use of lower doses of estrogens (20 $\mu \mathrm{g}$ vs $30 \mu \mathrm{g}$ ) and to a shorter HFI (24/4 vs 21/7 regimen). In addition, the discrepancy between the findings may have been related to the fact that they assessed different conditions, PMDD in one case and hormone withdrawal-associated symptoms in the other, and using different measurement scales. Such issues have been a constant problem in the analysis of studies that have investigated the effect of CHCs in PMS and PMDD. Populations tend to be heterogeneous, the inclusion criteria are sometimes not well defined, and measurement instruments vary.

There have also been attempts to assess the impact of continuous or extended contraceptive regimens on PMS, based on the supposition that eliminating the HFI while taking CHCs would have a positive effect on PMS and PMDD. A randomized clinical trial in which 386 women with PMDD were randomly allocated to taking an oral $\mathrm{CHC}$ containing $20 \mu \mathrm{g}$ of EE and $90 \mu \mathrm{g}$ of LNG on a continuous basis $(\mathrm{n}=186)$ or placebo $(P=181)$ over four 28-day cycles and completed the Daily Record of Severity of Problems found no significant differences between the two groups in the effect on PMDD at the end of the study period, while there were more adverse effects in the group taking oral contraceptives. ${ }^{48}$ Despite the fact that results were more favorable for oral CHCs in the first cycle, at the end of the study, after four cycles, this finding was not observed. ${ }^{49}$ 
In 2012, the results were published of a review that included three placebo-controlled randomized trials and one open-label, single-treatment substudy. The four studies assessed changes from baseline to the end of the treatment in a total of 622 women treated with a continuous regimen of $20 \mu \mathrm{g}$ of EE and $90 \mu \mathrm{g}$ of LNG. In all three clinical trials, the $\mathrm{CHC}$ was compared to placebo. Symptoms were assessed using the Daily Record of Severity of Problems or Penn Daily Symptom Rating questionnaire. Although questionnaire scores were found to improve, there were discrepancies between the studies, and a strong placebo effect was detected. The authors of the review concluded that the data, although not consistent, suggest that continuous LNG/EE may reduce the symptoms of PMDD and PMS and, hence, can be considered an option for women who are appropriate candidates for a continuous oral contraceptive for contraceptive purposes, the approved indication for this medication. ${ }^{50}$

\section{Effect of CHC estrogens on PMS}

It is well known that EE induces the activation of the reninangiotensin system in the liver, thereby increasing water retention and causing symptoms associated with this phenomenon. ${ }^{51}$ This action allows us to explain the physical symptoms associated with CHCs in the premenstrual phase: breast pain, abdominal bloating, weight gain, etc. Various different studies have demonstrated that EE stimulates liver angiotensin production $\sim 350$ times more strongly than estradiol, and hence it seems reasonable to expect a lower impact on the renin-angiotensin system if we use the latter hormone. ${ }^{52-54}$

It has been shown that during the use of an oral $\mathrm{CHC}$ using $\mathrm{EE}$, there is a marked drop in plasma levels of estrogen at the beginning of the $\mathrm{HFI},{ }^{55}$ attributable to the strong inhibition of follicular development by EE. In contrast, using a $\mathrm{CHC}$ containing estradiol, the initial decline associated with starting the HFI is compensated for by the simultaneous start of endogenous estradiol production. ${ }^{56}$

A CHC containing estradiol has shown a beneficial effect in women with menstrual migraine. Specifically, a prospective noncomparative study, which included 32 women diagnosed with menstrual migraine, used a $\mathrm{CHC}$ with estradiol valerate $(\mathrm{E} 2 \mathrm{~V})$ and dienogest over six cycles. The number of episodes of migraine significantly decreased with respect to baseline, after three $(P<0.001)$ and six cycles of use..$^{57}$

Recently, a pooled analysis of two clinical trials has been published that compared two types of $\mathrm{CHC},{ }^{58}$ one containing $30 \mu \mathrm{g}$ of $\mathrm{EE}$ and $3 \mathrm{mg}$ of drospirenone and the other $1.5 \mathrm{mg}$ of E2 and $2.5 \mathrm{mg}$ of nomegestrol acetate. These clinical trials used the Moos Menstrual Distress Questionnaire Form C, a standardized questionnaire containing 47 items grouped into eight domains. Of the 3,522 women recruited, 2,631 used the CHC with E2 and 891 used that with EE. The treatment with E2/nomegestrol acetate was more effective than the one based on $\mathrm{EE} /$ drospirenone in reducing menstrual and premenstrual symptoms, leading to a significant reduction in the scores of many of the Menstrual Distress Questionnaire Form C domains.

An observational, multicenter, prospective, Phase IV study examined changes in premenstrual and menstrual symptoms from baseline to 6 months in women who initiated combined oral contraception based on estradiol. Eligible women attending a gynecology appointment were classified into one of three groups: Group 1, using the barrier contraceptive method of condoms and choosing to continue with this method; Group 2, using condoms and choosing to switch to combined oral contraception based on natural estrogen; or Group 3, using combined oral contraception based on EE and choosing to switch to combined oral contraception based on natural estrogen. The Spanish Society of Contraception Quality of Life scale was used to assess health-related quality of life. Secondary outcomes included perception of PMS symptoms, intermenstrual bleeding, duration and intensity of menstrual bleeding, contraception continuation rate, and tolerability. Of 857 women enrolled, 785 completed the study. Using a visual analog scale to assess the intensity of a range of symptoms related to PMS, women in Group 2, who swapped from condoms to an estradiol-based $\mathrm{CHC}$, had a significant reduction in lumbar and lower abdominal pain, changes in sleep, irritability, and difficulty to concentrate..$^{59}$

\section{Conclusion}

Given the etiology of PMS and PMDD, it seems plausible to treat these entities using combined hormonal contraception. To date, the only oral $\mathrm{CHC}$ indicated for the treatment of PMDD is that containing drospirenone used in a $24 / 4$ regimen. However, there is evidence that other contraceptives can also have beneficial effects, especially in those with longer regimens and those containing estradiol rather than EE.

\section{Acknowledgment}

The authors alone are responsible for preparing and writing the manuscript.

\section{Disclosure}

Iñaki Lete has a financial relationship (lecturer, member of advisory boards, and/or consultant) with MSD, Teva, Adamed, HRA Pharma, and Nordic Pharma. Oihane Lapuente reports no conflicts of interest in this work. 


\section{References}

1. Halbreich U. The diagnosis of premenstrual syndromes and premenstrual dysphoric disorder clinical procedures and research perspectives. Gynecol Endocrinol. 2004;19(6):320-324.

2. Hylan TR, Sundell K, Judge R. The impact of premenstrual symptomatology on functioning and treatment-seeking behavior: experience from the United States, United Kingdom, and France. JWomens Health Gend Based Med. 1999;8(8):1043-1052.

3. Campbell EM, Peterkin D, O'Grady K, Sanson-Fisher R. Premenstrual symptoms in general practice patients. Prevalence and treatment. J Reprod Med. 1997;42(10):637-646.

4. Wittchen HU, Becker E, Lieb R, Krause P. Prevalence, incidence and stability of premenstrual dysphoric disorder in the community. Psychol Med. 2002;32(01):119-132.

5. World Health Organization. Mental, behavioural and developmental disorders. Tenth Revision of the International Classification of Diseases (ICD-10). Geneva: World Health Organization; 1966.

6. Halbreich U, Backstrom T, Eriksson E, et al. Clinical diagnostic criteria for premenstrual syndrome and guidelines for their quantification for research studies. Gynecol Endocrinol. 2007;23(3):123-130.

7. American Psychiatric Association. Diagnostic and Statistical Manual of Mental Disorders, Fifth Edition (DSM-5). Arlington: American Psychiatric Association; 2013.

8. Steiner M, Macdougall M, Brown E. The premenstrual symptoms screening tool (PSST) for clinicians. Arch Womens Ment Health. 2003;6(3):203-239.

9. Imai A, Ichigo S, Matsunami K, Takagi H. Premenstrual syndrome: management and pathophysiology. Clin Exp Obstet Gynecol. 2014;42(2):123-128.

10. Schmidt PJ, Nieman LK, Danaceau MA, Adams LF, Rubinow DR. Differential behavioral effects of gonadal steroids in women with and in those without premenstrual syndrome. $N$ Engl J Med. 1998;338(4):209-216.

11. Andréen L, Nyberg S, Turkmen S, van Wingen G, Fernández G, Bäckström T. Sex steroids induced negative mood may be explained by the paradoxical effect mediated by GABA modulators. Psychoneuroendocrinology. 2009;34(8):1121-1132.

12. Freeman EW. Luteal phase administration of agents for the treatment of premenstrual dysphoric disorder. CNS Drugs. 2004;18(7): $453-468$.

13. Usman SAB, Indusekhar R, O'Brien S. Hormonal management of premenstrual syndrome. Best Pract Res Clin Obstet Gynaecol. 2008;22(2):251-260.

14. Rapkin AJ, Morgan M, Goldman L, Brann DW, Simone D, Mahesh VB. Progesterone metabolite allopregnanolone in women with premenstrual syndrome. Obstet Gynecol. 1997;90(5):709-714.

15. Protopopescu X, Tuescher O, Pan H, et al. Toward a functional neuroanatomy of premenstrual dysphoric disorder. J Affect Disord. 2008;108(1):87-94.

16. Freedman EW. Premenstrual syndrome and premenstrual dysphoric disorder: definitions and diagnosis. Psychoneuroendocrinology. 2003;28:25-27.

17. Dueñas JL, Lete I, Bermejo R, et al. Prevalence of premenstrual syndrome and premenstrual dysphoric disorder in a representative cohort of Spanish women of fertile age. Eur J Obstet Gynecol Reprod Biol. 2011;156(1):72-77.

18. Adewuya AO, Loto OM, Adewumi TA. Pattern and correlates of premenstrual symptomatology amongst Nigerian university students. J Psychosom Obstet Gynecol. 2009;30(2):127-132.

19. Borenstein JE, Dean BB, Endicott J, et al. Health and economic impact of the premenstrual syndrome. J Reprod Med. 2003;48(7): 515-524.

20. Lete I, Dueñas JL, Serrano I, et al. Attitudes of Spanish women toward premenstrual symptoms, premenstrual syndrome and premenstrual dysphoric disorder: results of a nationwide survey. Eur J Obstet Gynecol Reprod Biol. 2011;159(1):115-118.
21. Marjoribanks J, Brown J, O’Brien PM, Wyatt K. Selective serotonin reuptake inhibitors for premenstrual syndrome. Cochrane Database Syst Rev. 2013;6:CD001396.

22. Shah NR, Jones JB, Aperi J, Shemtov R, Karne A, Borenstein J. Selective serotonin reuptake inhibitors for premenstrual syndrome and premenstrual dysphoric disorder: a meta-analysis. Obstet Gynecol. 2008;111(5):1175.

23. Kaur G, Gonsalves L, Thacker HL. Premenstrual dysphoric disorder: a review for the treating practitioner. Cleve Clin $\mathrm{J} \mathrm{Med.}$ 2004;71(4):303-321.

24. Wang M, Hammarbäck S, Lindhe BÅ, Bäckström T. Treatment of premenstrual syndrome by spironolactone: a double-blind, placebocontrolled study. Act Obstet Gynecol Scand. 1995;74(10):803-808.

25. Ford O, Lethaby A, Mol B, Roberts H. Progesterone for premenstrual syndrome. Cochrane Database Syst Rev. 2012;(3):CD003415.

26. O'Brien S, Rapkin A, Dennerstein L, Nevatte T. Diagnosis and management of premenstrual disorders. BMJ. 2011;342:d2994.

27. White AR. A review of controlled trials of acupuncture for women's reproductive health care. J Fam Plann Reprod Health Care. 2003;29(4):233-236.

28. Loch EG, Selle H, Boblitz N. Treatment of premenstrual syndrome with a phytopharmaceutical formulation containing Vitex agnus castus. J Womens Health Gend Based Med. 2000;9(3):315-320.

29. Yakir M, Kreitler S, Brzezinski A, Vithoulkas G, Oberbaum M, Bentwich Z. Effects of homeopathic treatment in women with premenstrual syndrome: a pilot study. Br Homeopath J. 2001;90(3):148-153.

30. Nevatte T, O'Brien PMS, Bäckström T, et al. ISPMD consensus on the management of premenstrual disorders. Arch Womens Ment Health. 2013;16(4):279-291.

31. Joffe H, Cohen LS, Harlow BL. Impact of oral contraceptive pill use on premenstrual mood: predictors of improvement and deterioration. Am J Obstet Gynecol. 2003;189(6):1523-1530.

32. Ross C, Coleman G, Stojanovska C. Factor structure of the modified Moos Menstrual Distress Questionnaire: assessment of prospectively reported follicular, menstrual and premenstrual symptomatology. J Psychosom Obstet Gynaecol. 2003;24(3):163-174.

33. Archer DF, Lasa IL. Tailoring combination oral contraceptives to the individual woman. J Womens Health (Larchmt). 2011; 20(6):879-891.

34. Monteleone P, Luisi S, Tonetti A, et al. Allopregnanolone concentrations and premenstrual syndrome. Eur J Endocrinol. 2000;142(3):269-273.

35. Breech LL, Braverman PK. Safety, efficacy, actions, and patient acceptability of drospirenone/ethinyl estradiol contraceptive pills in the treatment of premenstrual dysphoric disorder. Int JWomens Health. 2009;1:85.

36. Rapkin AJ, Sorger SN, Winer SA. Drospirenone/ethinyl estradiol. Drugs Today. 2008;44(2):133-145.

37. Parsey KS, Pong A. An open-label, multicenter study to evaluate Yasmin, a low-dose combination oral contraceptive containing drospirenone, a new progestogen. Contraception. 2000;61(2):105-111.

38. Freeman EW, Kroll R, Rapkin A, et al. Evaluation of a unique oral contraceptive in the treatment of premenstrual dysphoric disorder. J Womens Health Gend Based Med. 2001;10(6):561-569.

39. Pearlstein TB, Bachmann GA, Zacur HA, Yonkers KA. Treatment of premenstrual dysphoric disorder with a new drospirenone-containing oral contraceptive formulation. Contraception. 2005;72(6):414-421.

40. Yonkers KA, Brown C, Pearlstein TB, Foegh M, Sampson-Landers C, Rapkin A. Efficacy of a new low-dose oral contraceptive with drospirenone in premenstrual dysphoric disorder. Obstet Gynecol. 2005;106(3): 492-501.

41. Lopez LM, Kaptein AA, Helmerhorst FM. Oral contraceptives containing drospirenone for premenstrual syndrome. Cochrane Database Syst Rev. 2012;(2):CD006586

42. Foidart JM, Wuttke W, Bouw GM, Gerlinger C, Heithecker R. A comparative investigation of contraceptive reliability, cycle control and tolerance of two monophasic oral contraceptives containing either drospirenone or desogestrel. Eur J Contracept Reprod Health Care. 2000;5(2):124-134 
43. Kelly S, Davies E, Fearns S, et al. Effects of oral contraceptives containing ethinylestradiol with either drospirenone or levonorgestrel on various parameters associated with well-being in healthy women. Clin Drug Investig. 2010;30(5):325-336.

44. Wichianpitaya J, Taneepanichskul S. A comparative efficacy of low-dose combined oral contraceptives containing desogestrel and drospirenone in premenstrual symptoms. Obstet Gynecol Int. 2013;2013:487143.

45. Sulak PJ, Scow RD, Preece C, Riggs MW, Kuehl TJ. Hormone withdrawal symptoms in oral contraceptive users. Obstet Gynecol. 2000;95(2): 261-266.

46. Klipping C, Duijkers I, Trummer D, Marr J. Suppression of ovarian activity with a drospirenone-containing oral contraceptive in a 24/4 regimen. Contraception. 2008;78(1):16-25.

47. Bitzer J, Banal-Silao MJ, Ahrendt HJ, et al. Hormone withdrawalassociated symptoms with ethinylestradiol $20 \mu \mathrm{g} /$ drospirenone $3 \mathrm{mg}$ (24/4 regimen) versus ethinylestradiol $20 \mu \mathrm{g} /$ desogestrel $150 \mu \mathrm{g}(21 / 7$ regimen). Int $J$ Womens Health. 2015;7:501-509.

48. Halbreich U, Freeman EW, Rapkin AJ, et al. Continuous oral levonorgestrel/ethinyl estradiol for treating premenstrual dysphoric disorder. Contraception. 2012;85(1):19-27.

49. Kwan I, Onwude JL. Premenstrual syndrome. BMJ Clin Evidence. 2009; $12: 806$

50. Freeman EW, Halbreich U, Grubb GS, et al. An overview of four studies of a continuous oral contraceptive (levonorgestrel $90 \mathrm{mcg} / \mathrm{ethinyl}$ estradiol $20 \mathrm{mcg}$ ) on premenstrual dysphoric disorder and premenstrual syndrome. Contraception. 2012;85(5):437-445.

51. Halbreich U, Monacelli E. Some clues to the ethiology of premenstrual syndrome/premenstrual dysphoric disorder. Prim psychiatry. 2004;11:33-40.
52. Guengerich FP. Metabolism of $17 \alpha$-ethynylestradiol in humans. Life Sci. 1990;47(22):1981-1988.

53. Lobo RA, Stanczyk FZ. New knowledge in the physiology of hormonal contraceptives. Am J Obstet Gynecol. 1994;170(5):1499-1507.

54. Mashchak CA, Lobo RA, Dozono-Takano R, et al. Comparison of pharmacodynamic properties of various estrogen formulations. Am J Obstet Gynecol. 1982;144(5):511-518.

55. Duijkers IJ, Klipping C, Grob P, Korver T. Effects of a monophasic combined oral contraceptive containing nomegestrol acetate and $17 \beta$-oestradiol on ovarian function in comparison to a monophasic combined oral contraceptive containing drospirenone and ethinylestradiol. Eur J Contracept Reprod Health Care. 2010;15(5): 314-325.

56. Gerrits MG, Schnabel PG, Post TM, Peeters PA. Pharmacokinetic profile of nomegestrol acetate and 17 $\beta$-estradiol after multiple and single dosing in healthy women. Contraception. 2013;87(2):193-200.

57. Nappi RE, Terreno E, Sances G, et al. Effect of a contraceptive pill containing estradiol valerate and dienogest (E2V/DNG) in women with menstrually-related migraine (MRM). Contraception. 2013;88(3):369-375.

58. Witjes H, Creinin MD, Sundström-Poromaa I, Martin Nguyen A, Korver T. Comparative analysis of the effects of nomegestrol acetate/17 $\beta$-estradiol and drospirenone/ethinylestradiol on premenstrual and menstrual symptoms and dysmenorrhea. Eur J Contracept Reprod Health Care. 2015;20(4):296-307.

59. Lete I, de la Viuda E, Pérez-Campos E, et al. Effect on quality of life of switching to combined oral contraception based on natural oestrogen: an observational, multicentre, prospective, phase 4 study (ZOCAL Study). Eur J Contracept Reprod Health Care. 2016;21(4):276-284.
Open Access Journal of Contraception

\section{Publish your work in this journal}

Open Access Journal of Contraception is an international, peerreviewed, open access, online journal, publishing original research, reports, reviews and commentaries on all areas of contraception. In addition to clinical research, demographics and health-related aspects, the journal welcomes new findings in animal and preclinical studies

\section{Dovepress}

relating to understanding the biological mechanisms and practical development of new contraceptive agents. The manuscript management system is completely online and includes a very quick and fair peer-review system. Visit http://www.dovepress.com/testimonials.php to read real quotes from published authors. 